\title{
CONSTITUIÇÃO SIMBÓLICA: A DISCREPÂNCIA ENTRE O SIMBOLISMO CONSTITUCIONAL E SUA INEFICÁCIA NORMATIVO-JURÍDICA
}

Kaio César da Silva Mota ${ }^{289}$

Recebido em: 19/04/2016

Aprovado em: 01/08/2016

\section{RESUMO}

Este trabalho apresenta estudo acerca da "Constituição Simbólica: a discrepância entre o simbolismo constitucional e sua ineficácia normativo-jurídica". Abordar-se-á o tema discorrendo sobre a discrepância entre o simbolismo substancial implicado na Constituição Federal brasileira e sua ineficácia normativo-jurídica, muito em razão da influência da função político-simbólica, utilizando-se como fundamento basilar a obra de Pierre Bourdieu, remetendo-se, obviamente, a outros teóricos a fim de complementar os pontos fulcrais do tema. A partir de uma abordagem sistemático-dedutiva sobre o tema, será possível identificar a discrepância entre o simbolismo substancial implicado no texto constitucional e sua ineficácia normativo-jurídica provocada pela influência da função político-simbólica.

Palavras-chave: Constituição simbólica. Constitucionalização. Simbólico. Legislação Simbólica. Legislação-álibi.

\section{INTRODUÇÃO}

Com o advento da Constituição Cidadã, assim denominada a Constituição Federal do Brasil de 1988, criou-se a expectativa de se ver vários direitos sociais concretizados. O mens legislatoris que viabilizou a inserção de preceitos normativos e principiológicos não encontrados nas Constituições anteriores, provocou a crença de que surgira, com a vigente Lex Fundamentalis, a norma garantidora da democracia brasileira, legitimando o Estado a se intitular democrático de direito.

É recorrente no universo jurídico a discussão sobre a eficácia dos dispositivos legais já efetivados, haja vista que a coercitividade da lei não é recurso suficiente para concretizar esse

\footnotetext{
${ }^{289}$ Graduado em Direito pela Universidade Estácio de Sá. Assessor do Juizado Especial do Tribunal de Justiça do Rio Grande do Norte. Endereço eletrônico: kaiomota@tjrn.jus.br.
} 
escopo. Fala-se, por exemplo, das garantias individuais preconizadas pela Lei Fundamental, direitos que vão desde a isonomia entre os indivíduos, passando pela liberdade de crença e expressão, até os direitos sociais, tais como: saúde, moradia, trabalho, habitação, etc.

Abordar o tema, mesmo que num plano restrito, ensejará repetidas discussões acerca da eficácia da lei, especialmente quanto à concretização normativo-jurídica dos textos constitucionais, por conseguinte desenvolvendo mecanismos racionais a fim de alcançar a formação do ordenamento social e jurídico idealizados pelas normas; a paz social tão almejada e pregada na Carta Magna.

Até mesmo aos olhos do leigo, por vezes é hipoteticamente previsível quando uma norma não tem a mínima probabilidade de concretização. A própria dinâmica social, sujeita às influências político-ideológicas incidentes durante os vários períodos da história brasileira, determinam a falácia normativo-jurídica que certas normas projetam.

Através de método hermenêutico, notadamente lógico-sistemático, a teor de interpretações jurídico-sociológicas doutrinárias, utilizando-se de obras clássicas de autores como Pierre Bourdieu, Kindermann, Cassirer, Lévi-Strauss, Luhmann, Marcelo Neves, Fábio Nadal, além de outros autores alemães, tomando-se por base, ainda, o que já foi publicado em relação ao tema, compreender-se-á o assunto sob a ótica jurídico-filosófica de modo que se possa delinear uma nova abordagem, chegando à conclusões que possam servir de embasamento para pesquisas futuras.

Obviamente será necessário se remeter não poucas vezes à Constituição da República e a outras leis infraconstitucionais do ordenamento jurídico pátrio para ilustrar as acepções apropriadas ao tema, para, assim, confrontar-se com o debate sobre legislação simbólica e delimitar os pontos fracos existentes no ordenamento vigente, identificando as deficiências normativas a serem repensadas, ou mesmo expurgadas, com vistas a torná-las plenamente eficazes.

Apesar da abordagem eminentemente constitucional, faz-se mister, complementarmente, demonstrar o simbolismo existente em outros textos legais infraconstitucionais. Por exemplo, no tocante ao sistema penal, cujas normas, em alguns casos, são remissões do próprio disposto constitucional.

Os debates que o assunto possa provocar imputarão aos atores envolvidos no âmbito das ciências jurídicas, sociais e políticas a incumbência de reavaliar todos os elementos que propiciam ou impedem a eficácia normativo-jurídica da Constituição, em boa parte tendo a influência que sofre da função político-ideológica como fator causador. Por conseguinte, 
almeja-se, a partir de tais debates, a criação de pressupostos que revistam o texto constitucional não só de simbolismo, mas de eficácia.

É nesse diapasão que, de forma minuciosa, serão demonstrados primeiramente os limites adequados da semântica do termo "simbólico", numa intersecção entre os significados atribuídos por Bourdieu e Neves para adjetivar o texto constitucional. Após, analisar-se-á o problema da concretização normativa do texto legal, fenômeno não restrito ao Codex Magno. Em seguida, conceituar-se-á a função político-simbólica, para, enfim, analisar como se dá a influência desse fenômeno jurídico-político como fator objetivador da ineficácia normativojurídica do texto constitucional.

Somente através desse iter analítico se alcançará o bojo de conhecimento basilar para compreender a discrepância entre o simbolismo substancial implicado no texto constitucional e sua ineficácia normativo-jurídica, provocada pela influência da função político-simbólica.

\section{DELIMITAÇÃO DO CONCEITO “SIMBÓLICO”}

\subsection{SEMÂNTICA DO SIMBÓLICO}

Sobre o "simbólico" surgiram diversas conceituações através dos tempos e ciências, difundidas nas diversas áreas de produção cultural, sem que houvesse, contudo, predefinições dogmáticas acerca da semântica do termo. Não bastassem as ciências divergirem sobre a definição ideal do fenômeno em seus próprios ambientes autônomos, inexiste unanimidade nas lições dos respectivos teóricos.

Segundo afirma Bourdieu (1998, p. 08), a tradição neokantiana, adotada por HumboldtCassirer, ou na vertente norte-americana, por Sapir-Whorf, discorre acerca dos diversos universos simbólicos - mito, língua, arte, ciência - como mecanismos de cognoscibilidade e de construção da dimensão dos objetos, como "formas simbólicas", identificando, como verifica Marx em Teses sobre Feurbach (1984), o “aspecto ativo do cognoscível”. Corroborando, porém numa perspectiva histórica, Panofsky, também citado por Bourdieu (1998), discorre acerca do termo sem levar em consideração a análise sistemática das condições sociais implicantes.

Filosoficamente, utiliza-se o termo "simbólico" quando da demonstração de todos os mecanismos relacionais entre sujeito e realidade, culminando-se na transcendentalização de um poder de construção da realidade que tende a estabelecer essa ordem gnosiológica. 
Bourdieu (1998, p. 08) assevera que Durkheim, em contrapartida, "lança os fundamentos de uma sociologia das formas simbólicas [...]. Com Durkheim, as formas de classificação deixam de ser formas universais (transcendentais) para se tornarem (como implicitamente em Panofsky) em formas sociais, isto é, arbitrárias [...] e socialmente determinadas". Nesse sentido, os símbolos se apresentam como os "instrumentos por excelência da integração social, surgindo assim a premissa de que a ordem social é a reprodução do mundo social, em que a integração lógica é a condição da integração moral” (BOURDIEU, 1998, p. 10).

A teoria marxista, por sua vez, privilegia as funções políticas dos sistemas simbólicos em detrimento da sua estrutura lógica e da sua função gnosiológica, afastando-se plenamente das concepções comuns de Durkheim e Radcliffe-Brown (BOURDIEU, 1998, p. 09). Para Marx, os efeitos difundidos pelo simbólico relacionam-se intimamente com os interesses da classe dominante, servindo aos "interesses particulares que tendem a apresentar como interesses universais, comuns aos conjuntos do grupo" (BOURDIEU, 1998, p. 10).

Numa perspectiva antropológica, Neves apreende as palavras de Lévi-Strauss para afirmar que "toda cultura pode ser considerada como um conjunto de sistemas simbólicos em cuja linha de frente colocam-se a linguagem, as regras matrimoniais, as relações econômicas, a arte, a ciência, a religião" (LÉVI-STRAUS, 1974 apud NEVES, 2007, p. 7).

Vê-se, portanto, que diante de tantas conceituações, não há como delimitar o significado do termo simbólico atribuindo à sua semântica uma única definição adequada, haja vista que a ideal dependerá do campo teórico em que esteja sendo aplicada. Neste jaez, mostra-se inviável discorrer sobre as definições imputadas ao vocábulo sem prejuízo de se olvidar os grandes baluartes teóricos que discorreram sobre o assunto, pelo que, para centralização do termo ao objeto deste estudo, prevalecer-se-á de sua aplicação exclusivamente no campo do Direito.

\subsection{SIMBÓLICO NO DIREITO}

Como visto alhures, flutuam conceituações acerca do termo simbólico pelos vários campos teóricos: psicanálise, semiótica, lógica, antropologia, sociologia - sobretudo na teoria dos sistemas de Niklas Luhmann quanto a este último campo teórico -, e, obviamente, também no direito.

Para melhor compreensão do estudo sob a ótica do direito, abstrai-se o sentido adjetivador atribuído por Neves, em que o termo "aponta para o predomínio, ou mesmo hipertrofia, no que se refere ao sistema jurídico, da função simbólica da atividade legiferante e 
do seu produto - a lei -, sobretudo em detrimento da função jurídico-normativa" (NEVES, 2007, p. 23). Nesse sentido, como abstrair concretamente o simbólico no direito?

Pierre Bourdieu foi um dos pioneiros a responder essa indagação. Segundo ele, o poder simbólico reveste a lei de um poder putativo, invisível, o qual só pode ser exercido através da outorga de quem se submete inconscientemente. Assim, ao passo em que aqueles submetidos ao poder o legitimam, também não querem saber se estão sujeitos ou mesmo que o exercem. Há, portanto, uma relação de legitimidade e submissão permanente, cujos efeitos são observados no próprio estado social típico, no qual inexiste espaço para anomia.

Bourdieu (1998, p. 188) aduz acerca do poder simbólico como sendo "um poder que aquele que lhe está sujeito dá àquele que o exerce um crédito com que ele o credita, uma fides, uma autoritas, que ele confia pondo nele a sua confiança”. É um poder que tem sua existência condicionada à crença proveniente de quem a ele se sujeita, na expectativa de obter uma vantagem posterior.

Apropriando-se do tema, Marcelo Neves, em sua obra A constitucionalização simbólica, discorre sobre esse poder simbólico e suas implicações sobre os textos constitucionais, especialmente na perspectiva da Constituição brasileira. O estudo de Marcelo Neves se utilizou de outra obra. Trata-se de $O$ poder simbólico escrito por Bourdieu em 1989, que aborda a incidência do poder simbólico nos variados habitus científicos. Nesse sentido, conceitua Bourdieu (1998, p. 23) acerca do habitus:

\footnotetext{
Uma regra feita homem ou, melhor, um modus operandi científico que funciona em estado prático segundo as normas da ciência sem ter estas normas na sua origem: é esta espécie de sentido do jogo científico que faz com que se faça o que é preciso fazer no momento próprio, sem ter havido necessidade de tematizar o que havia que fazer, e menos ainda a regra que permite gerar a conduta adequada.
}

$\mathrm{Na}$ verdade, o autor expõe seu entendimento atravessando pelos vários campos da ciência que possuem estrutura estruturada, sem a qual não há possibilidade de existência do sistema simbólico, tendo em vista a imprescindibilidade de um ambiente apto a ser regulado; que possua regulamentações (Ibidem, p. 09).

Mesmo limitado à aplicação jurídica, o conceito de "simbólico" é bastante expansivo, e não se exaure numa definição universal, todavia se alia ao direito em razão de sua subsistência se dar, comumente, em virtude dos elementos implicantes da função política sobre o texto normativo-legal. O simbólico surge como o elemento favorável no contexto da constituição simbólica, mesmo havendo em contrapartida disfunção normativo-jurídica. 
Observando as implicações que o simbólico imprime no campo jurídico, constata-se inevitavelmente que o Direito é o poder simbólico por excelência, em razão de ele determinar o que são as coisas e possuir os instrumentos de controle social, podendo modificar e reger os rumos da história. Nesse sentido, trazem-se à baila as seguintes palavras de Bourdieu (1998, p. 237):

O direito é, sem dúvida, a forma por excelência do poder simbólico de nomeação que cria as coisas nomeadas e, em particular, os grupos; ele confere a estas realidades surgidas das suas operações de classificação toda a permanência, a das coisas, que uma instituição histórica é capaz de conferir às instituições históricas. O direito é a forma por excelência do discurso atuante, capaz, por sua própria força, mas com a condição de se não esquecer que ele é feito por este.

Factualmente, merecem acolhimento os dizeres do sociólogo, visto que são as normas jurídicas símbolos que controlam a conduta humana e que determinam aos indivíduos - seus subjugados - obediência à ordem social apregoada, sem questionamentos; sem possibilidade de escolha na aquiescência às suas determinações, demonstrando-se numa adesão quase cega, mítica, à base de fé.

Evidencia-se, desse modo, que em se tratando do universo jurídico, o poder simbólico subsistirá nesse campo teórico enquanto puder impingir seus efeitos sobre o texto normativolegal. Nesse sentido, tem-se que o poder que legitima a validade das normas se mostra tão grande que toda uma ordem societária, falando-se não só dos componentes (indivíduos), mas de tudo aquilo que compõe os diferentes universos simbólicos (ciência, língua, arte, mito), submetem-se aos preceitos impingidos em seu corpo textual. No entanto, tamanha força não é suficiente para concretizar tudo aquilo que preconiza, conduzindo à busca da compreensão do paradoxo existente: simbolismo demasiado à sua legitimação em detrimento da ineficácia normativo-jurídica.

\section{LEGISLAÇÃO SIMBÓLICA}

Sob uma ótica genérica e minimalista, pode-se definir legislação simbólica como sendo a falta de eficácia - obstáculo à consolidação do texto normativo - e efetividade - teleologia para a qual foi criada a norma.

O ordenamento jurídico pátrio adotou a sistemática aplicando-se o esquema da pirâmide normativa de Hans Kelsen, na qual a Constituição se encontra no topo. Encontra-se nessa posição justamente por ser parâmetro de efetivação e subsistência de qualquer texto normativo 
infraconstitucional. Isto é, não pode haver norma jurídica no ordenamento que não esteja em consonância com as normas impressas na Constituição Federal vigente.

Em sendo assim, não há que se falar em incidência do poder simbólico exclusivamente ao texto constitucional, tampouco às legislações infraconstitucionais. Verifica-se, outrossim, uma relação íntima entre esses extratos normativos.

Sendo a Constituição a norma ápice de uma sociedade, é de certo que estando imbuída de simbolismo, especialmente devido à influência de fatores ligados à política e à economia, sujeitará todo ordenamento jurídico às implicações desse poder simbólico nela implicado.

Mesmo que a força simbólica não manifeste seus efeitos em todas as normas do ordenamento jurídico vigente, a sujeição deste estará ininterruptamente vinculada enquanto o texto constitucional não obtiver pressupostos de eficácia.

Neves define a legislação simbólica "como produção de textos cuja referência manifesta à realidade é normativo-jurídica, mas que serve, primária e hipertroficamente, a finalidades políticas de caráter não especificamente normativo-jurídico” (NEVES, 2007, p. 30).

Com efeito, a análise acurada acerca atuação do legislativo brasileiro impõe a conclusão de que, na atuação do parlamento, para que não convém ao legislador, quando da pretensão de produzir leis, "tomar nenhuma providência no sentido de criar pressupostos para garantir sua eficácia, apesar de estar em condições de criá-los". Nesse instante "há indício de legislação simbólica", isto é, desabilitada da mínima eficácia e furtivamente afeita a interesses mais políticos particulares do que sociais abrangentes (Ibidem, p. 31).

Kindermann, aduzido e corroborado por Neves, criou um modelo de identificação da legislação simbólica. Nesse modelo, Kindermann propõe que, para a existência de legislação simbólica, é imprescindível a verificação de três requisitos cumulativos, quais sejam: “a) confirmar valores sociais, b) demonstrar a capacidade de ação do Estado, e c) adiar a solução de conflitos sociais através de compromissos dilatórios" (KINDERMANN, 1988 apud NEVES, 2007, p. 33).

Teleologicamente, o conteúdo da legislação simbólica deve obedecer ao menos a uma hipótese dentre aquelas que a caracterizam. O modelo tricotômico de Kindermann, cujo sistema é o mais adequado, é consequentemente o adotado neste estudo, guardadas as devidas distinções cabíveis, mesmo com as quais não se desnatura a classificação do teórico.

De certo não se pode esperar que determinada ação legislativa, com intenção aprioristicamente simbólica, resulte a posteriori em lei que venha a ser revestida de força normativa capaz de atingir seu escopo. Do mesmo modo, nada impede que leis advindas de ações legislativas com escopo instrumental possam, com o passar do tempo, adquirir "caráter 
predominantemente simbólico" (KINDERMANN, 1988, p. 225, apud NEVES, 2007, p. 30). Isto é, há possibilidade de que determinado diploma legal, cuja eficácia é plena numa época específica, e cujo simbolismo é exacerbado, perca sua capacidade de atingimento ao objetivo para o qual foi editado e, de todo modo, ainda seja caracterizado pelo excesso de simbolismo.

Com efeito, o problema da legislação simbólica não se restringe à intenção do legislador, sendo relevante observar os fatores e condições sociais implicantes na atuação legislativa, consoante se verificará mais à frente.

Importante ressaltar que a legislação simbólica também é utilizada para postergar a solução de demandas sociais através de "compromissos dilatórios", expressão pioneiramente usada por Schmitt (1970) quando discorreu acerca do tema em relação à constituição de Weimar.

$\mathrm{Na}$ perspectiva brasileira, podem-se apontar as normas constitucionais de eficácia limitada, por exemplo o direito de greve, capitulado no artigo 37, inciso VII, da Constituição da República Federativa do Brasil. O aludido direito ainda não foi regulado por lei específica, deixando à mercê do judiciário os limites e procedimentos adequados ao exercício desse direito.

Ocorre que o tratamento dado aos diferentes grupos profissionais, públicos ou privados, não é equânime, adotando-se determinadas regras jurisprudenciais em relação a um grupo e não a outro. Essa prática garante ao Executivo ou ao empregador a permissão jurídica para interferir sempre que entender como "abusiva" a greve.

Em relação especificamente ao poder público, o tratamento jurídico é bem mais desprovido de segurança jurídica, porquanto não tem interesse na regulamentação do direito de greve em razão de poder arguir contra todo ato grevista o "interesse público". Há muito mais interesse em adiar o conflito político entre o poder público e os empregadores privados, de um lado, com os empregados públicos ou privados do outro, tudo com vistas a satisfazer a vontade minoritária.

A legislação simbólica não apresenta apenas efeitos negativos - ausência de normatividade -; a contrario sensu, delineia-se também em um sentido positivo: "ela produz efeitos relevantes para o sistema político, de natureza não especificamente jurídica" (NEVES, 2007, p. 53), consoante se verá em capítulo próprio.

Conclui-se, à luz da lição de Neves (2007, p. 42), que a legislação simbólica "teria, então, efeitos sociais latentes, em muitos casos bem mais relevantes do que os 'efeitos manifestos' que lhe faltaram”. Nada obstante não atingirem seu escopo jurídico, qual seja, a concretização normativa do texto legal, os efeitos que deveriam repercutir na sociedade subsistem, contudo, sem resolver realmente os problemas sociais latentes. 


\section{A FUNÇÃo POLÍTICO-SIMBÓLICA}

Crê-se, como já dito, que a influência da função político-simbólica é bastante incidente na formação do seguinte paradoxo: força simbólica demasiada em detrimento da eficácia normativo-jurídica. Sendo assim, será de bastante valia a apropriação das acepções de Bourdieu (1998) acerca da "representação política" e sua "teoria do campo político" para a compreensão da influência da função política sobre a Norma Normarum. Bourdieu (1998, p. 172) expõe de forma clara a verdadeira dinâmica legislativa por trás de todos os mecanismos de compromisso dilatório:

O político avisado é o que consegue dominar praticamente o sentido objectivo e o
efeito social das suas tomadas de posição graças ao domínio que ele possui do espaço
das tomadas de posição actuais e, sobretudo, potenciais ou, melhor, do princípio
dessas tomadas de posição, a saber, o espaço das posições objectivas no campo e das
atitudes dos seus ocupantes: este "sentido prático" das tomadas de posição possíveis
e impossíveis, prováveis e improváveis, para os diferentes ocupantes das diferentes
posições, é o que lhe permite "escolher" as tomadas de posição convenientes e
convencionadas, e evitar as tomadas de posição "comprometedoras" que fariam com
que se encontrasse com os ocupantes de posições opostas no espaço do campo
político.

O político legislador se utiliza de todos os mecanismos que o próprio campo político lhe proporciona para agir em proveito de sua própria subsistência nesse universo. Não se deixa submeter às decisões que possam comprometer sua posição, mas, sim, atua da forma mais conveniente aos seus interesses, avençando com seus representados aquilo que muito provavelmente será cumprido, ou, no mínimo, não nos moldes pactuados.

Desde tempos idos, a política se utiliza da lei para impor suas vontades. “A Constituição na acepção moderna é fator e produto da diferenciação funcional entre direito e política como subsistemas da sociedade" (NEVES, 2007, p. 65). Apesar de não se enfocar a perspectiva lassaleana, vale a apropriação da expressão "fatores reais de poder" para definir a funcionalidade do texto constitucional nas mãos do Estado-legislador (LASSALE, 1998). Aqueles que detêm o "poder" constituinte podem muito facilmente utilizá-lo em seu favor, buscando atingir objetivos de um grupo exclusivo. Sobre o tema, afirma Nadal (2006, p. 46):

A importância da correlação entre política e Direito torna-se relevante com o surgimento do Estado de Direito - simultaneamente, instituição política e jurídica que visa à aplicação/imposição do Direito para o alcance do desenvolvimento jurídico, bem como a adaptação das circunstâncias sociais cambiantes aos fins políticos realizáveis. 
Celso Ribeiro Bastos (1999, p. 21), apropriando-se dos dizeres de Gonzalez Casanova (1994), fornece excelente argumento sobre essa relação:

\begin{abstract}
É corrente comprovar que, para muitos teóricos do Estado e, em especial, para muitos estudiosos do mesmo, Estado e comunidade política organizada seriam ideias sinônimas. Certas formas primitivas de organização social, dotadas de um rudimental sistema de governo (as polis gregas, o Império Romano, a pluralidade de centros de poder da Idade Média europeia), seriam tipos ou formas históricas de Estado, tal qual o Estado Moderno. Tem-se falado, portanto, do Estado despótico do antigo Egito, do Estado grego ou romano, do Estado feudal etc.
\end{abstract}

Nesse diapasão, a funcionalidade do Direito "torna-se um instrumento importante para o alcance dos fins políticos" (NADAL, 2006, p. 46). Daí a utilização dos instrumentos jurídicosimbólicos a serviço da função política, a fim de impor ou legitimar a dominação pretendida ou exercida; a contribuição para "assegurar a dominação de uma classe sobre outra (violência simbólica) dando reforço da sua própria força às relações de força que as fundamentaram e contribuindo assim, segundo a expressão de Max Weber, para a 'domesticação dos dominados"” (BOURDIEU, 1998, p. 11). Nesse sentido, afirma Neves (2007. p. 29):

\footnotetext{
Observa-se que há um grande número de leis que servem apenas para codificar juridicamente "normas sociais" reconhecidas. Por outro lado, a complexidade do ambiente social dos sistemas jurídico e político é muito acentuada para que a atuação do Estado através de legislação possa ser apresentada como instrumento seguro de controle social.
}

Ocorre que, por vezes, as demandas sociais se apresentam diante do legislador como exigência para que ele se posicione a respeito de problemas da sociedade, a fim de gestar leis que tratem especificamente de cada demanda, apresentando-se como resolução somente o fato de elas existirem, sem, contudo, importar-se com a eficácia normativa da lei gestada. A isso Neves (2007, p. 33) denomina “forma de reconhecimento da 'superioridade' ou predominância social de sua concepção valorativa”.

Neves, citando Luhmann, afirma que "trata-se de um caso típico de 'exploração' do sistema jurídico pela política. Não se configura aqui uma 'exploração' eventual ou em aspectos isolados, mas sim uma 'superexploração' generalizada. Daí porque se fala em 'sociedade hiperpolitizada' em casos de constitucionalização simbólica”, posto que o intenso processo de politização que influencia na ordem legislativa esteve tão presente na elaboração da Constituição de 1988 quanto está contemporaneamente interferindo na elaboração de novas leis infraconstitucionais (NEVES, 2007, 151).

De outro ponto, verifica-se que os efeitos mais danosos provocados pela função políticosimbólica ocorrem quando esse fenômeno implica sua atuação diretamente no texto 
constitucional, visto que é esse texto normativo o de maior valor jurídico em uma sociedade constituída à base do Estado de Direito. Ver-se-á oportunamente a relação da função política com o texto constitucional.

\section{LEGISLAÇÃO-ÁLIBI}

$\mathrm{Na}$ perspectiva de Kindermann, a pressão do público imposta ao legislador é considerada fator preponderante e, via de regra, motivador da ação que resulta na criação de leis simbólicas, visto que, para atender às expectativas daqueles de quem depende sua carreira política, elabora normas sem que haja o mínimo de condições de sua efetivação. A esse tipo de legislação simbólica, Kindermann (1988 apud NEVES, 2007, p. 36) denominou de "legislaçãoálibi”.

É comum nos períodos eleitorais o político-legislador provocar o merecimento de sua manutenção baseando seu desempenho no fato de ter participado, senão ensejado, a criação de leis condizentes com os anseios apresentados por seus representados. Com o argumento de que o período do mandato não corresponde ao tempo hábil para que a lei surta seus efeitos teleológicos na sociedade, o político induz o eleitorado a colocar em segundo plano a importância da concretização das normas incutidas na lei.

Em razão da insatisfação da população por não ver sair do papel aquilo que poderia dirimir muitos de seus problemas, a atuação afirmativa do legislador é utilizada como álibi para abrandar o descontentamento do povo diante do Estado, que se torna figura idônea e legitimada não pelo desenvolvimento social em todas as suas concepções, mas, embora com "boas intenções", por inserir leis falaciosas no ordenamento jurídico, abarrotando-o de forma reprovável e despicienda.

Pode-se citar na experiência brasileira a chamada "Lei Maria da Penha". Trata-se da Lei $\mathrm{n}^{\circ}$ 11.340/06, que "cria mecanismos para coibir a violência doméstica e familiar contra a mulher [...]; dispõe sobre a criação dos Juizados de Violência Doméstica e Familiar contra a Mulher; altera o Código de Processo Penal, o Código Penal e a Lei de Execução Penal; e dá outras providências" (BRASIL, 2006).

Atentando-se especificamente às medidas protetivas de urgência que obrigam o agressor, previstas no artigo 22 da referida lei, tem-se evidente exemplo de legislação-álibi em razão de o legislador não ter criado os pressupostos que viabilizassem a ininterrupta efetivação da medida específica. Senão vejamos: na hipótese de o agressor ser coagido às medidas dos 
incisos II e III $^{290}$ do art. 22 da referida lei, não há como o Estado garantir sua efetivação constante, porquanto inexiste previsão de que a autoridade policial, ou outro órgão competente, impeça o contato do agressor com a ofendida permanentemente.

É de conhecimento notório os vários casos em que vítimas de homicídio já eram amparadas pelas medidas protetivas da Lei Maria da Penha, todavia seus algozes não obedeceram ao preceito mandamental de se manterem afastados. Ao contrário, burlaram a ordem legal e praticaram o crime mais hediondo do nosso ordenamento penal: o homicídio.

Traz-se à baila o seguinte comentário de Isolete Cristóvão (2008, p. 14):

\begin{abstract}
Na aplicação da regra da justiça ao caso concreto podem ocorrer dois casos anômalos: a equidade, entendida como adaptação da norma ao caso singular, que não permite uma perfeita equiparação com os casos previstos, e o privilégio, entendido como isenção de um dever geral ou atribuição de um direito particular a uma pessoa ou categoria singular. A primeira permite corrigir uma possível desigualdade que resultaria da aplicação rígida da norma geral, e, portanto, não viola a regra de justiça. $\mathrm{O}$ segundo introduz uma desigualdade não prevista, e, portanto, viola a regra de justiça.
\end{abstract}

No que tange a esse aspecto da lei, evidencia-se a inserção de preceitos com o escopo primário de apenas abrandar as exigências do grupo interessado, haja vista que não se verificam pressupostos que garantam a eficácia da lei, muito embora o legislador se exima de qualquer culpa, transferindo-a comumente a outros sistemas na tentativa de incutir no eleitorado a premissa de que sua competência se esgota na elaboração da lei, sendo obrigação do executivo a sua efetividade.

Com efeito, preconiza Neves que a legislação-álibi é decorrência da tentativa de aparentar que os respectivos problemas da sociedade estão sendo dirimidos. Por consequência disso, o público se convence das boas intenções do legislador (NEVES, 2007, p. 39). "Como se tem observado, ela não apenas deixa os problemas sem solução, mas, além disso, obstrui o caminho para que eles sejam resolvidos. Nesse sentido, pode-se afirmar que a legislação-álibi

\footnotetext{
${ }^{290}$ Art. 22. Constatada a prática de violência doméstica e familiar contra a mulher, nos termos desta Lei, o juiz poderá aplicar, de imediato, ao agressor, em conjunto ou separadamente, as seguintes medidas protetivas de urgência, entre outras:

$[\ldots]$

II - afastamento do lar, domicílio ou local de convivência com a ofendida;

III - proibição de determinadas condutas, entre as quais:

a) aproximação da ofendida, de seus familiares e das testemunhas, fixando o limite mínimo de distância entre estes e o agressor;

b) contato com a ofendida, seus familiares e testemunhas por qualquer meio de comunicação;

c) freqüentação de determinados lugares a fim de preservar a integridade física e psicológica da ofendida;

IV - restrição ou suspensão de visitas aos dependentes menores, ouvida a equipe de atendimento multidisciplinar ou serviço similar;

$\mathrm{V}$ - prestação de alimentos provisionais ou provisórios.
} 
constitui uma forma de manipulação ou de ilusão que imuniza o sistema político contra outras alternativas" (Ibidem).

Ressalte-se que a legislação-álibi nem sempre mantém sua função simbólica. Lembrese que função simbólica está ligada à crença do povo na eficácia da lei somente em razão de sua existência, mas não de sua concretização. Portanto, o emprego indiscriminado da legislação-álibi tenderá na mesma proporção ao fracasso. A lição de Neves (Ibidem, p. 41) é bem clara:

O emprego abusivo da legislação-álibi leva à "descrença” no próprio sistema jurídico, "transtorna persistentemente a consciência jurídica", Tornando-se abertamente reconhecível que a legislação não contribui para a positivação de normas jurídicas, o direito como sistema garantidor de expectativas e regulador de condutas cai em descrédito; disso resulta que o público se sente enganado, os atores políticos tornamse cínicos.

Atesta-se, portanto, quão grande influência determinada lei pode sofrer do legisladorpolítico, cuja função, condicionada ao voto do cidadão, é de ver seus representados satisfeitos através de sua atuação, elaborando leis que, a teor de sua função simbólica, apenas aparentam resolver os problemas e expectativas apresentadas pelo eleitorado.

\section{A CONSTITUCIONALIZAÇÃO SIMBÓLICA}

\subsection{A CONSTITUIÇÃO DA REPÚBLICA FEDERATIVA DO BRASIL DE 1988}

A Constituição Federal vigente no ordenamento jurídico brasileiro foi promulgada em 05 de outubro de 1988, atendendo aos anseios de diferentes classes sociais e representações políticas. A referida Constituição foi pseudonominada “Constituição Cidadã”, em razão de, pela primeira vez, incutir direitos e garantias fundamentais que pouco, ou nunca, inseriram-se em textos constitucionais pretéritos; são definidos os direitos dos cidadãos, sejam eles individuais, coletivos, sociais ou políticos, e são estabelecidos limites para o poder dos governantes.

Após o fim do regime militar, em todos os segmentos da sociedade era unânime a necessidade de uma nova Carta, pois a anterior (1967) havia sido "promulgada" em pleno regime ditatorial militar, por uma Assembleia Constituinte que foi obrigada pelos militares a votá-la e aprová-la, evidenciando sua mera promulgação simbólica.

Além disso, não se pode olvidar que a Carta de 1967 fora modificada várias vezes com emendas arbitrárias (vide AI-5). 
Diante disso, após diversas manifestações populares, em $1^{\circ}$ de fevereiro de 1987, foi instalada a Assembleia Nacional Constituinte, composta por 559 congressistas (senadores e deputados federais, eleitos no ano anterior), e presidida pelo deputado Ulysses Guimarães, filiado ao Partido do Movimento Democrático Brasileiro - PMDB.

Representando um avanço em direção à democracia, a sociedade, em seus diversos setores, foi estimulada a contribuir por meio de propostas. As propostas formuladas por cidadãos brasileiros só seriam válidas se representadas por alguma entidade - associação, sindicato, etc. - e se fossem assinadas por, no mínimo, trinta mil pessoas. Os setores da sociedade, compostos por grupos que procuravam defender seus interesses, fizeram pressão por meio de lobbies.

Em relação às constituições anteriores, a Constituição de 1988 representa um avanço. As modificações mais significativas foram: direito de voto para os analfabetos; voto facultativo para jovens entre 16 e 18 anos; redução do mandato do presidente de 05 para 04 anos; eleições em dois turnos (para os cargos de presidente, governadores e prefeitos de cidades com mais de 200 mil habitantes); os direitos trabalhistas passaram a ser aplicados, além de aos trabalhadores urbanos e rurais, também aos domésticos; direito à greve; liberdade sindical; diminuição da jornada de trabalho de 48 para 44 horas semanais; licença maternidade de 120 dias (tendo sido ampliada para 180 dias); licença paternidade de 05 dias; abono de férias; décimo terceiro salário para os aposentados; seguro desemprego; férias remuneradas com acréscimo de 1/3 do salário, etc.

Obviamente nossa Constituição está lapidada sob a égide do positivismo. É composta por um "conjunto de regras codificado e sistematizado em um único documento, para fixar-se a organização fundamental" (MORAES, 2010, p. 28). Canotilho (2007, p. 65) denomina-a de constituição instrumental, apontando seu efeito racionalizador, estabilizante, de segurança jurídica e de calculabilidade e publicidade. Segundo Barroso (2009, p. 74), a Constituição, em sentido formal, "é a norma fundamental e superior, que regula o modo de produção das demais normas do ordenamento jurídico e limita o seu conteúdo".

Mas o que nos intreressa nessa abordagem legislativa é delimitar a atuação da Constituição, como implica e como é implicada pela força simbólica.

Demonstrou-se anteriormente que a relação entre política e direito (norma) acoplamento estrutural segundo Marcelo Neves - ocorre de tal modo que o poder políticosimbólico exerce função transcendente desde logo na própria Constituição do Estado, revelando-se os efeitos desse poder em "uma comunidade transformada pelo exercício sobre ela" (BASTOS, 1999, p. 28). 
O simbólico se insere nesse contexto desde os primórdios do constitucionalismo. Isso porque a Constituição nasceu de ideais (ideologias) jamais pensadas, ou, talvez, jamais confiadas à concretude.

Nadal (2006, p. 106), discorrendo sobre a teleologia do mito-constituição, afirma que "é na idelogia que o mito-constituição vai basear seu discurso visando realizar suas tarefas (implantação, regulação, simbólica e representação)". Nesse sentido, traz-se à baila a afirmação de Luzia Marques da Silva Cabral Pinto (1994, p. 218-219), de que "todas as realidades de hoje foram utopias de ontem".

Vê-se, desse modo, que a discussão sobre a aplicabilidade das normas constitucionais foram, desde seu nascedouro, alvos de descrença, pois verificava-se amplos obstáculos à sua aplicabilidade devido às influências de fatores reais de poder (LASSALE, 1998), de modo que até hoje existem elementos dificultantes à normatividade jurídico-constitucional.

Ora, sabe-se que os direitos fundamentais foram conquistados mediante extensas, colossais, e odisseicas lutas durante a história. Provavelmente o Iluminismo tenha sido o evento histórico mais relevante entre os que se possam estabelecer como paradigmas das conquistas de direitos fundamentais. Foi durante a exsurgência dos clarões iluministas que se construíram teorias basilares à formação da Constituição verdadeiramente revestida de "direito".

Thomas Hobbes, com sua obra Leviatã (1651), trabalho que muito influenciou o Contrato Social de Rousseau (1752) - embora de argumentação contrária acerca da origem dos conflitos humanos -, assevera que o caos ou a guerra civil - situações identificadas como um estado de natureza e pelo famoso lema bellum omnium contra omnes (guerra de todos contra todos) - só poderia ser evitado por um governo central forte. Propõe uma ideia de "poder comum" hierarquicamente superior aos contratantes, com força (poder coercitivo) suficiente a impor o cumprimento, uma vez que "os vínculos das palavras são demasiado fracos para refrear a ambição, a avareza, a cólera e outras paixões dos homens, se não houver o medo de algum poder coercitivo" (HOBBES, 2003, p. 119). Esse poder comum-coercitivo seria o poder constitucional que une os cidadãos de uma mesma sociedade a um conjunto de regras a serem cumpridas com o intuito de manter a ordem racional e a paz social.

Enquanto isso, John Locke tratava sobre o governo civil - Dois Tratados sobre o Governo (1689). A primeira parte descreve a condição corrente do governo civil, enquanto a segunda parte descreve a justificação para o governo e os ideais necessários à sua viabilização. Sobre o direito à propriedade, seu maior legado, Locke (1998, p. 510) afirma: 
Portanto, dado que os homens em sociedade possuem propriedade, têm eles sobre os bens que, com base na lei da comunidade, lhes pertencem, um direito tal que a ninguém cabe o direito de tolher seus haveres, ou partes destes, sem o seu próprio consentimento; sem isso, não teriam propriedade nenhuma.

De outro ponto, Montesquieu - Do Espírito das Leis (1748) -, inspirado em Locke, propunha a tripartição dos poderes (legislativo, executivo, e judiciário) como mecanismo para melhor gestão da sociedade e desenvolvimento racional da humanidade. $\mathrm{O}$ artigo $2^{\circ}$ Constituição de 1988, por exemplo, assegura que "são Poderes da União, independentes e harmônicos entre si, o Legislativo, o Executivo e o Judiciário" (BRASIL, 1988). Sobre o tema, preconizou Montesquieu (1996, p. 84):

Em todo Estado há três espécies de poderes, o Poder Legislativo, o Poder Executivo das coisas que dependem do Direito das gentes e o Poder Executivo das coisas que dependem do Direito civil. Pelo primeiro o Príncipe ou Magistrado faz leis para algum tempo ou para sempre, e corrige ou ab-roga as que estão feitas. Pelo segundo, ele faz a paz ou a guerra, envia e recebe embaixadas, estabelece a ordem, previne invasões. Pelo terceiro, pune os crimes e julga os dissídios dos particulares. Chama-se a última o poder de julgar e a outra simplesmente Poder Executivo do Estado.

Ainda não se olvida de Jean-Jacques Rousseau, que ofereceu O Contrato Social (1752) como proposta de uma sociedade unida sob a proteção de um indivíduo escolhido como representante do povo. Ari dos Santos Pinto Júnior (2011), discorrendo sobre a influência do Contrato Social rousseauniano nos princípios fundamentais da Constituição da República Federativa do Brasil, afirma:

\footnotetext{
Na obra $O$ Contrato Social, Rousseau procura criar soluções para a sociedade que passara de um estado de natureza, marcado pela liberdade, igualdade e amor de si, para a vida social, surgindo a propriedade privada, o amor próprio e neste momento se vê a necessidade da criação do contrato social. A Constituição da República Federativa do Brasil, promulgada em 1988, prevê nos direitos fundamentais, ideias que se assemelham com as do filósofo, sendo marcante na Constituição Brasileira sua influência.
}

Todos esses pensadores contribuíram para a instalação de constituições de distintas formas. Pode-se afirmar que a Constituição brasileira possui em seu cerne centelhas de todos esses teóricos, talvez sendo uma das constituições teoricamente mais equilibradas dentre as que figuram no Estado moderno, não obstante sua deficiência normativo-jurídica no que tange a determinados preceitos. Ressalte-se que a normatividade jurídica eficiente não está vinculada ao texto em si, mas em pressupostos que possibilitem sua concretização.

Contudo, por diversos fatores, tal como a função simbólica, dispositivos constitucionais não conseguem passar da morte à vida. Diz-se assim porquanto muitas normas capituladas nas constituições figuram apenas como letra morta, isso de forma geral. 
A Constituição de 1988, mormente quanto aos princípios fundamentais, sobretudo quando do alcance desses princípios pela massa - leiam-se indivíduos pertencentes às classes sociais marginalizadas/bestializadas -, também requerem maior progresso a fim de que se extinga, ou ao menos se mitigue, a carga de simbolismo à qual estão sujeitos, atingindo, por conseguinte, nível adequado de normatividade jurídica, e cumprindo a função social para a qual foram idealizados, muito embora isso também dependa da mudança de mentalidade da sociedade, vez que a lei, por si só, não consegue atingir tal escopo.

\title{
6.2 CONSTITUCIONALIZAÇÃO-ÁLIBI
}

A partir dos pressupostos de legislação simbólica tratados anteriormente, bem como à luz da fórmula utilizada por Kindermann para definir legislação simbólica, destacam-se três formas básicas de manifestação simbólica no texto constitucional: "1) a constitucionalização simbólica destinada à corroboração de determinados valores sociais; 2) a Constituição como fórmula de compromisso dilatório; 3) a constitucionalização-álibi” (NEVES, 2007, p. 102).

Discorrer-se-á sobre a primeira espécie no próximo subcapítulo deste trabalho. No que tange ao segundo item, vide capítulo acerca da legislação simbólica. Neste tópico tratar-se-á especificamente da constitucionalização-álibi.

Neves (2007, p. 36), apropriando-se do entendimento de Kindermann, discorre sobre a legislação-álibi, tratando-a como a atuação política do legislador, geralmente coagido, na elaboração de leis que satisfaçam às "expectativas dos cidadãos", deixando em segundo plano as condições de efetivação, olvidando-se, portanto, dos pressupostos de normatividade-jurídica. Neves (2007, p. 37) afirma o seguinte:

\footnotetext{
Nos períodos eleitorais, por exemplo, os políticos prestam conta do seu desempenho, muito comumente, com referências à iniciativa e à participação no processo de elaboração de leis que correspondam às expectativas do eleitorado. [...] Importante é que os membros do parlamento e do governo apresentem-se como atuantes e, portanto, que o Estado-Legislador mantenha-se merecedor da confiança do cidadão.
}

E complementa (Ibidem, p. 123):

\begin{abstract}
Mediante a legislação simbólica, os órgãos estatais demonstrariam cenicamente seu interesse e disposição de solucionar problemas em princípio estruturalmente insolúveis. A legislação-álibi constituiria, então, um típico mecanismo de promoção da "lealdade das massas" no Estado de bem-estar..
\end{abstract}

Bourdieu já se referia à Constituição como "álibi" em sinônimo de "símbolo". No entanto, não há que se falar em sinônimos em relação às expressões. Existe, a bem da verdade, 
a função da constituição simbólica como álibi, caracterizando-se por ser político-ideológica, seja para disfarçar problemas sociais vigentes, seja para garantir a estabilidade dos atores presentes no sistema governamental.

Bryde (1982, p. 29) enceta o caminho para o entendimento da atuação das constituições simbólicas como álibi. Para ele, “as 'Constituições Simbólicas', em oposição às 'normativas', fundamentam-se, sobretudo, nas 'pretensões' da elite dirigente pela representação simbólica de sua ordem estatal". No entanto, a definição que se entende mais adequada à constitucionalização-álibi é exprimida por Neves (2007, p. 105):

Delas não decorre nenhuma modificação real no processo de poder. No mínimo, há um adiamento retórico da realização do modelo constitucional para um futuro remoto, como se esta fosse possível sem transformações radicais nas relações de poder e na estrutura social.

Um exemplo de legislação simbólica - legislação-álibi para Kindermann - que implicou efeitos de constitucionalização-álibi, em razão da interpretação do princípio da isonomia, foi o debate constitucional nos átrios do Supremo Tribunal Federal ocorrido em 2012, que tratou das cotas raciais nas instituições de ensino superior.

O STF julgou constitucional a delimitação de vagas nas universidades destináveis exclusivamente a afrodescendentes. Analisando-se detidamente o objeto da ADI, verifica-se não ser complexa sua compreensão.

Ocorre que o argumento fulcral que determinou a constitucionalidade da referida norma (MP no 213/04) se baseou na dívida histórica que o Estado adquiriu em relação aos negros. É sabido que, por séculos, eles foram escravizados e privados de direitos fundamentais básicos (liberdade, igualdade, dignidade da pessoa humana, etc.). Em razão disso, criou-se o entendimento de que o Estado devia recompensar os erros pretéritos com ações afirmativas até ser atingido um verdadeiro estágio de adimplemento de seu débito histórico. Para tanto, fora determinado através da Medida Provisória ante citada a destinação de vagas exclusivamente para negros nas universidades públicas. Seria uma forma de mitigar a dívida com os afrodescendentes, até hoje alvos de discriminação racial, implícita ou explicitamente.

Não obstante a inegável dívida histórica do Estado com os negros, faz-se mister denunciar o condão de legislação-álibi existente tanto na MP n 213/04 quanto na decisão do STF (ADI 3330, 2012) que reconhece a constitucionalidade da norma.

Ora, por mais que se reconheça a disparidade histórica de tratamento, não se pode olvidar que nem todos os negros necessitam de tais cotas para ingressar no ensino superior, haja 
vista que muitos possuem poder aquisitivo suficiente a obter educação de qualidade durante sua formação básica.

Não se afirma, contudo, que a dívida histórica do Estado foi "paga" em relação aos indivíduos afrodescendentes. O que se ataca, outrossim, são os mecanismos com os quais se procura equilibrar o tratamento dispensado aos indivíduos em geral, quais sejam: as cotas raciais nas instituições de ensino superior.

O sistema de cotas não proporciona tratamento equânime, tampouco adimple sua dívida de segregação histórica com os negros, visto que não há isonomia, proporcionalidade, razoabilidade, tampouco respeito à coletividade quando, hipoteticamente, um afrodescendente de classe social razoável, formado basilarmente nas melhores escolas particulares do país, tem acesso ao ensino superior através da prerrogativa das cotas. E, por outro lado, um indivíduo não afrodescendente, mesmo sendo pobre e tendo estudado durante toda a vida em escolas públicas precárias - fator principal da disparidade educacional - não poderá gozar da mesma prerrogativa. Afinal, as cotas são somente para negros, não para quaisquer indivíduos, malgrado sejam menos abastados.

A ineficácia da dívida se encontra exatamente na prerrogativa disponibilizada a determinado grupo em detrimento notório do princípio da isonomia, visto que a suposta dívida será paga em relação a uns indivíduos e a outros não. Não está se impondo justiça através da equidade, mas sim em detrimento do esquecimento de outro grupo de indivíduos, que não pode pagar pela omissão Estatal histórica. Sobre isso, vejamos a lição de Bobbio, verbis (1992, p. 10):

\footnotetext{
$\mathrm{Na}$ aplicação da regra da justiça ao caso concreto podem ocorrer dois casos anômalos: a equidade, entendida como adaptação da norma ao caso singular, que não permite uma perfeita equiparação com os casos previstos, e o privilégio, entendido como isenção de um dever geral ou atribuição de um direito particular a uma pessoa ou categoria singular. A primeira permite corrigir uma possível desigualdade que resultaria da aplicação rígida da normal geral, e portanto não viola a regra de justiça. O segundo introduz uma desigualdade não prevista, e portanto viola a regra de justiça.
}

O melhor parâmetro a ser adotado no caso em tela seria o econômico, visto que índios também sofreram com a colonização, tentativa de escravização, e dizimação No entanto, não serão contemplados com tal benefício (cotas para negros). Inclusive, nesse sentido votou o ministro Gilmar Mendes; não negou a dívida histórica com os negros, mas advertiu sobre o parâmetro equivocado adotado (STF, ADI 3330, 2012).

Necessário se faz a inserção de um adendo quanto às cotas para indígenas. Na região Norte do Brasil já existem instituições de ensino superior que disponibilizam cotas para 
indígenas. Crê-se algo muito preocupante esse sistema de cotas. Diz-se isso, porquanto se vislumbra o caminhar de uma nação para a segregação explícita e legal, visto que só fomenta, pejorativamente, a divisão de um único povo.

Obviamente não é de se olvidar que o Brasil é um país miscigenado, repleto de regionalismos; uma verdadeira síntese de culturas, sendo, portanto, multiculturado. Daí pergunta-se: o sistema de cotas é o melhor mecanismo para gerar o equilíbrio entre os grupos raciais e étnicos - que sofreram com a segregação histórica, nas suas mais variadas formas? Crê-se que não. Não obstante, é um debate amplo, que enseja distintas vertentes argumentativas. Por isso, deixa-se seu aprofundamento para outro momento.

Felizmente já em alguns Estados se utiliza o parâmetro econômico. Também são utilizados outros parâmetros, como no Rio de Janeiro, por exemplo, que adota o regime de cotas para estudantes de escola pública, deficientes, indígenas, e até para filhos de policiais militares e civis.

Embora se compreenda a boa intenção do legislador-político, boa intenção essa inerente à legislação-álibi, não se pode olvidar que, direta ou indiretamente, estar-se diante da segregação, vez que as cotas tratam desigualmente os iguais, senão em relação à sua cultura ou condição física, mas em relação à sua condição social, posto que independente de serem portadores de deficiência ou não, filhos de policiais ou não, foram atingidos pelas mesmas mazelas sociais e sujeitados à mesma educação defasada e ineficiente.

Retornando ao conceito de legislação-álibi, especialmente sua relação com o ordenamento pátrio, "pode-se afirmar que a legislação-álibi constitui uma forma de manipulação ou de ilusão que imuniza o sistema político contra outras alternativas, desempenhando uma função “ideológica”" (NOLL, 1982 apud NEVES, 2007, p. 39-40). Nesse plano, inegável a adequação com o sistema político pátrio.

\subsection{A CONSTITUCIONALIZAÇÃO SIMBÓLICA}

Quando os indivíduos em geral ou determinados grupos desviam seu comportamento ao ponto de infringirem os preceitos constitucionais mediante procedimentos eleitorais, legislativos, judiciais e administrativos, de tal modo que o ideal constitucional transubstanciase em um álibi, verifica-se a configuração da constitucionalização simbólica (NEVES, 2007).

Verifica-se em sede de constituição simbólica a existência relacional entre códigosdiferença discorridos por Luhmann (2010), que implicam diretamente na deficiência normativo-jurídica do texto constitucional. 
Na visão da teoria dos sistemas de Luhmann, os âmbitos da economia, da política, da ciência, da religião, da moral etc., não estão dispostos a se submeterem ao código-diferença "lícito/ilícito" preconizado por Kelsen.

O “ter/não-ter" econômico e o "poder/não-poder" político se sobrepõem de tal modo sobre o "lícito/ilícito" normativo-jurídico de Kelsen que, "no caso da constitucionalização simbólica, ocorre o bloqueio permanente e estrutural da concretização dos critérios/programas jurídico-constitucionais pela injunção de outros códigos sistêmicos e por determinações do "mundo da vida"' (NEVES, 2007, p. 93).

Em um mundo globalizado, ligado por laços econômicos tênues entre os Estados, a economia dita regras capazes de violar, ou no mínimo modificar, as constituições vigentes. É a partir do "ter/não-ter" que se assegura o "poder/não-poder". Enquanto o código binário econômico cria regras sobre o código político, este se vale do Direito, sobrepondo-se ao código "lícito/ilícito", a fim de subsistir no sistema.

Nos dizeres de Niklas Luhmann (apud NADAL, 2006, p. 50), “com a democratização, o sistema político se expõe aos atrativos de decidir iniciativas para a modificação do Direito". Desse modo, “o direito fica subordinado à política, mas a uma política pulverizada, incapaz de generalização consistente e, pois, de autonomia operacional” (NEVES, 2007, p. 152).

Essa subordinação ocorre de forma mais contundente quando se refere às injunções do código "ter/não-ter" (economia), tudo devido à ausência de "um sistema normativo-jurídico constitucional eficaz e socialmente vigente", em que os "atores políticos" não sejam mais suscetíveis às influências imediatas dos interesses particularistas (Ibidem, p. 151-152).

Neves, parafraseando Luhmann, discorre sobre o tema em Entre a Têmis e Leviatã: uma relação difícil (2006, p. 218), afirmando que:

\footnotetext{
O problema da sociedade mundial como condicionamento negativo do Estado Democrático de Direito reside no fato de que se trata de uma sociedade que se reproduz primariamente com base no código econômico. O código "ter/não-ter" configura-se como o mais forte e, por reproduzir-se regularmente além de fronteiras, torna o sistema econômico relativamente "intocável" pelos Estados enquanto sistemas jurídico-políticos diferenciados segmentariamente em territórios.
}

Coaduna justamente com os requisitos da legislação-álibi apresentados por Kindermann (1988), para o qual o interesse na permanência de detenção do poder é alcançado através da manipulação do direito, construindo diplomas normativos que somente aparentam demonstrar suprir as necessidades dos cidadãos. Assim, conseguem dar legitimidade à sua atuação, angariando a aprovação do eleitorado. 
A contrario senso, vê-se o "bloqueio permanente e generalizado do código 'lícito/ilícito' pelos códigos ‘ter/não-ter' (economia) e 'poder/não-poder' (política)”, implicando numa prática político-jurídica que desafia o princípio da legalidade (NEVES, 2007, p. 146).

Apropriando-se das palavras de Luhmann (1980), estar-se-á diante de um caso típico de "exploração" do sistema jurídico pela política. Nesse sentido:

\begin{abstract}
A politização particularista da administração impede a concretização generalizada dos princípios constitucionais da legalidade, "moralidade" e "impessoalidade". A corrupção e as fraudes eleitorais impossibilitam a legitimação constitucional (generalizada) do sistema político, que passa, então, a subordinar-se instavelmente aos interesses particularistas de cima e às necessidades concretas de baixo, sendo constrangido a adotar mecanismos substitutivos de "legitimações casuísticas" inconstitucionais, como favores, concessões, ajudas e trocas ilícitas. (NEVES, 2007, 161).
\end{abstract}

Contudo, não se trata simplesmente de violação, prevaricação, ou mesmo omissão quanto aos preceitos normativos. Antes disso, para que se configure o efeito negativo da constitucionalização simbólica, é preciso que o discurso político seja perpetrado, comumente, com vistas ao benefício de uma minoria, todavia com o aval da maioria, pois esta vislumbra o engendramento normativo como benesse genérica.

Desse modo, a função política consegue demonstrar aos cidadãos o grande potencial de normatização legislativa, quando na verdade não passa de mero simbolismo, pois de certo que sua finalidade será “adiar a solução de conflitos sociais" (KINDERMANN, 1988, apud Neves, 2007, p. 81).

Nesse sentido, destaca-se a seguinte lição de Neves (2007, p. 123):

\footnotetext{
Mediante a legislação simbólica, os órgãos estatais demonstrariam cenicamente seu interesse e disposição de solucionar problemas em princípio estruturalmente insolúveis. A legislação-álibi constituiria, então, um típico mecanismo de promoção da "lealdade das massas" no Estado de bem-estar.
}

Ademais, o problema da constitucionalização simbólica influencia a própria ordem social, visto que seus efeitos se reproduzem através das dimensões material, social e temporal, pois "em não havendo suficiente relevância normativo-jurídica dos textos constitucionais, compromete-se o direito como um sistema autônomo fundamentado na congruente generalização de expectativas normativas nas dimensões citadas” (NEVES, 2007, p. 150).

Nesse sentido, a Constituição faz por merecer o epíteto de Carta Política, revelando-se situada em papel meramente retórico, na medida em que se vê obstada de servir mais ao código "lícito/ilícito" do que aos demais códigos-diferença, especialmente o político ("poder/não- 
poder”) e o econômico (“ter/não-ter”). Trata-se de ver retirada da Constituição a característica fulcral de juridicidade, fundamento do sentido moderno do Estado de direito.

Nesse sentido, “a constitucionalização atua como álibi: o 'Estado' se apresenta como identificado com os valores constitucionais", alegando implicitamente que esses não se concretizam atualmente por culpa exclusiva da sociedade subdesenvolvida. Vejamos o seguinte argumento de Neves (2007, p. 186):

\begin{abstract}
Em face da realidade social discrepante, o modelo constitucional é invocado pelos governantes como álibi: transfere-se a "culpa" para a sociedade "desorganizada" e "atrasada", "descarregando-se" de "responsabilidade" o Estado ou governo constitucional. No mínimo, transfere-se a realização da Constituição para um futuro remoto e incerto.
\end{abstract}

Apesar de entre seus objetivos estar o de propiciar "a confiança dos cidadãos no respectivo governo ou, de um modo geral, no Estado" (KINDERMANN, 1988 apud NEVES, 2007), sabe-se que o texto constitucional tem como finalidade bem mais que isso, tornando-se constituição simbólica quando, outrossim, serve somente a interesses de uma determinada classe.

Obviamente não se pretende afirmar que a Constituição Federal, em sua plenitude, é desprovida de ineficácia normativo-jurídica. Não obstante, as características intrínsecas de poder simbólico são verificadas em alguns preceitos constitucionais, essencialmente nas normas que dizem respeito aos direitos e garantias fundamentais, onde se vê estratosférica carga de poder simbólico, todavia, imensos obstáculos à sua efetividade/eficácia.

No entanto, é a partir da incidência do poder simbólico na Constituição brasileira, e da ideia de legislação-álibi, mediante a atuação da função político-simbólica (legislador), que se verifica o paradoxo entre o imensurável simbolismo constitucional e sua substancial ineficácia normativo-jurídica.

A ausência de normatividade jurídica de alguns dispositivos constitucionais está vinculada à sua função hipertroficamente simbólica. Em face da realidade social, os governantes transferem a culpa da ineficácia de alguns preceitos constitucionais, bem como de algumas legislações infraconstitucionais, para a sociedade, desenvolvendo a retórica falaciosa de que aquela é incapaz de vivenciar a concretização normativa em virtude de seu atraso e desorganização social.

O fenômeno da constitucionalização simbólica está de tal modo arraigada na Constituição brasileira que salta aos olhos o quão discrepante é a força simbólica que possuem determinados dispositivos legais - especialmente no que tange aos considerados mais valiosos 
- em detrimento de sua capacidade de produzir efeitos eficazes em favor da sociedade que deles se valem. Neste pórtico, para uma mudança radical, imprescindível a "inclusão do público pluralisticamente organizado no processo interpretativo, ou melhor, no processo de concretização constitucional", para que a normatividade do texto constitucional seja obtida de forma consentânea aos níveis de desenvolvimento social permanente (NEVES, 2007, p. 86).

\section{CONSIDERAÇÕES FINAIS}

O presente estudo buscou identificar a discrepância entre o simbolismo substancial implicado no texto constitucional em detrimento de sua ineficácia normativo-jurídica, provocada pela influência da função político-simbólica.

A partir da delimitação semântica do termo "simbólico", enfocado no campo teórico do direito, pode-se adotar conceituação adequada ao desenvolvimento do presente trabalho, muito embora não haja uma definição singular acerca da significação do termo. Com efeito, o fenômeno do simbólico não é exclusivo do direito, ou de qualquer outro campo teórico, tampouco se pode resumir sua incidência no texto constitucional.

Por outro lado, é certo que a ciência jurídica é simbólica por excelência, posto que as normas jurídicas nada mais são que a linguagem simbólica controladora da conduta de um indivíduo em sociedade, sob as quais os membros de uma coletividade a elas se sujeitam espontaneamente, cumprindo suas obrigações e aderindo aos direitos subjetivos alheios.

Presume-se que os indivíduos de uma dada sociedade, ao edificarem o direito que irá reger as suas relações sociais e limitar a satisfação de suas necessidades, aceitam como legítimo tanto o poder que cria as normas, quanto validam (aceitam) o conteúdo destas, já que, do contrário, existiria, possivelmente, um contexto de subversão política, vez que se questiona a obediência ao estatuto social criado pelo poder político-simbólico.

Nesse sentido, não há o direito sem a incidência do simbólico, tampouco sociedade sem direito, haja vista este ser um fenômeno social que tem por escopo o controle comportamental de uma coletividade que visa o status quo progressivo.

Há um ciclo de dependência mútua que conduz o indivíduo societário em um plano cultural produzido pelo acúmulo de valores histórico-culturais, os quais jamais deixarão de exsurgir e criar novos elementos simbólicos naquela determinada sociedade.

Ademais, não se pode olvidar que o poder originário constituinte emana do povo, razão pela qual se deve salientar acerca da maior relevância que possui o simbólico no texto 
constitucional. Nele estão contidos os dispositivos encetadores da ordem social, os quais refletem as maiores consequências na ordem jurídica vigente.

Sendo a Constituição o ápice da norma num dado ordenamento jurídico, bem como o reflexo para todas as outras normas hierarquicamente inferiores, é de se conceber que a função simbólica que nela incide é, atraindo o conceito filosófico, o princípio primeiro da ordem jurídico-social.

O simbólico se relaciona com o direito sem distinguir o texto legal no qual produzirá seus efeitos. Isso porque sua incidência está condicionada a fatores que exsurgem por razões subjetivas, e sujeita toda e qualquer norma, bastando o preenchimento dos requisitos que caracterizam a legislação simbólica ou a legislação-álibi, a depender se a norma apenas não possui eficácia normativo-jurídica ou, se além disso, não a possui em virtude de ter sido elaborada como forma de compromisso dilatório, isto é, um álibi para a sociedade.

Com efeito, o problema da concretização normativo-jurídico, independente se com vistas à configuração de legislação simbólica ou legislação-álibi, é provocada, comumente, pela função político-simbólica a qual está sujeita a norma, porquanto incumbe ao legislador, cuja função é alcançada através de processo político-eleitoral, a elaboração dos dispositivos normativos com vistas ao alcance de interesses substancialmente políticos.

Verifica-se problema mais gravoso quando o fenômeno do simbólico atinge não uma norma infraconstitucional, mas quando o próprio texto normativo constitucional é implicado, haja vista que, possivelmente, os efeitos do simbolismo implicado na Constituição emanarão para todo o ordenamento jurídico, dada sua característica de reflexibilidade.

A demasiada carga de simbolismo é incutida de forma a secundarizar a eficácia normativo-jurídica da norma, mormente causada pela função política (Estado-legislador), que para permanecer em destaque cria engodos normativos com o escopo de ludibriar a sociedade, demonstrando pretensa atuação funcional, quando em verdade não revestem os diplomas legais elaborados com os devidos pressupostos de concretização.

É plenamente cabível aduzir que a concretização normativa do texto constitucional está condicionada a uma radical revolução nas relações de poder. Somente com uma sociedade politizada será possível atingir o conceito legítimo de Estado Democrático de Direito, vez que no governo (Estado) democrático impossível conceber a ideia de afastamento da participação efetiva dos cidadãos (povo).

No entanto, isso não seria possível sem que primeiro houvesse acesso à educação de qualidade. Não há que se falar em sociedade politizada sem que haja sociedade "educada". Somente com o acesso à educação os cidadãos poderiam atingir tal nível de compreensão que 
adquiririam conhecimento político o bastante para proceder à atuação e fiscalização adequada do sistema político. São processos condicionados: educação (compreensão), politização (atuação) e democracia (concretização constitucional).

Para tanto, é realmente preciso haver uma "revolução", pois a conquista e a efetivação da cidadania não advirão apenas da declaração dos direitos fundamentais insertos na Constituição. É imprescindível a força normativa da Constituição, ou seja, a sua integração ao vivenciar e agir dos cidadãos e agentes públicos na forma de direitos e deveres recíprocos.

É preciso propiciar a legítima implantação do Estado Democrático de Direito, nada obstante as várias barreiras e pressões político-sociológicas que se opõem à sua realização imediata.

Desse modo, a "constitucionalização simbólica" será mitigada, e o paradoxo relacional entre a normatividade constitucional e a função política, ao invés de atrair o simbolismo como fator adjetivador, coexistirá numa legítima interação político-jurídica, posto que a autonomia operacional do direito é atingida, comumente por influência da função política.

\section{REFERÊNCIAS}

BARROSO, Luís Roberto. Curso de direito constitucional contemporâneo. 2. ed. São Paulo: Saraiva, 2010.

BASTOS, Celso Ribeiro. Curso de direito constitucional. 20. ed. atual. São Paulo: Saraiva, 1999.

BOBBIO, Norberto. A era dos direitos. 11. ed. Rio de Janeiro: Campus, 1992.

BOURDIEU, Pierre. O poder simbólico. Tradução Fernando Tomaz (português de Portugal). 2. ed. Rio de Janeiro: Bertrand Brasil, 1998.

BRASIL. Constituição (1988). Constituição da República Federativa do Brasil. Brasília: Senado Federal, 2009.

BRASIL. Lei Federal No 11.340, de 07 de agosto de 2006. Lei Maria da Penha. Brasília: Senado Federal, 2012.

BRYDE, Otto. Verfassungsentwicklung, Stabilität uns Dynamik im Verfassungsrecht der Bundesrepublik Deutschland, Baden-Baden, 1982. 
CANOTILHO, J. J. Gomes. Direito constitucional e teoria da constituição. 7. ed. Coimbra: Almedina, 2007.

CASANOVA, José Antonio Gonzalez. Teoria del estado y derecho constitucional. Imprenta: Barcelona, Vicens Vives, 1994.

CRISTÓVÃO, Isolete. As medidas protetivas da Lei Maria da Penha: reestruturação ou desestruturação do núcleo familiar. 2008. 80 pag. Monografia (Graduação em Direito) Universidade do Vale do Itajaí, Biguaçu, SC, 2008.

HOBBES, Thomas. Leviatã. Trad. João Paulo Monteiro e Maria Beatriz Nizza da Silva. São Paulo: Martins Fontes, 2003.

KELSEN, Hans. Teoria Pura do Direito. 6. ed. São Paulo : Martins Fontes, 2000.

LASSALE, Ferdinand. A essência da constituição. 4. ed. Rio de Janeiro: Lumen Juris, 1998.

LÉVI-STRAUSS, Claude. Introduction a l'oeuvre de Marcel Mauss. In: Marcel Mauss. Sociologie et Anthropologie. 5. ed. Paris: Presses Universitaires de France, vol. I. pp. IX-LII [1 $1^{\text {a }}$ ed. 1950] [trad. bras.: Introdução à obra de Marcel Mauss. In: Marcel Mauss. Sociologia e antropologia. São Paulo: EPU/Edusp, 1974, vol. I, pp. 1-36].

LOCKE, John. Dois tratados sobre o governo. Trad. Júlio Fischer. São Paulo: Martins Fontes, 1998.

LUHMANN, Niklas. Legitimação pelo procedimento. Tradução Maria da Conceição CôrteReal. Brasília: Editora Universidade de Brasília, 1980.

Introdução à teoria dos sistemas. Tradução Ana Cristina Arantes Nasser. 2. ed. Rio de Janeiro: Vozes, 2010.

MARX, Karl. A ideologia alemã: 1. Capítulo seguido das teses sobre Feuerbach. São Paulo: Moraes, 1984.

MONTESQUIEU, Charles de Secondat, Baron de. O espírito das Leis. Trad. Cristina Murachco. São Paulo: Martins Fontes, 1996. 
MORAES, Alexandre. Direito constitucional. 20. ed. São Paulo: Atlas, 2010.

NADAL, Fábio. A Constituição como mito: o mito como discurso legitimador da constituição. São Paulo: Método, 2006.

NEVES, Marcelo. A constitucionalização simbólica. São Paulo: WMF Martins Fontes, 2007.

Entre Têmis e Leviatã: uma relação difícil. O Estado Democrático de Direito a partir e além de Luhmann e Habermas. [tradução do autor]. São Paulo: Martins Fontes, 2006.

PINTO, Luzia Maria da Silva Cabral. Os limites do poder constituinte e a legitimidade material da constituição. Coimbra: Coimbra Editora, 1994.

PINTO JÚNIOR, Ari da Silva. A influência do Contrato Social de Rousseau nos princípios fundamentais da Constituição da República Federativa do Brasil. 2011. Disponível em: $<$ http://www.webartigos.com/artigos/a-influencia-do-contratosocial-de-rousseaunosprincipios-fundamentais-da-constituicao-darepublicafederativa-do-brasil/6 7486/\#ixzz1vuKnqRzz>. Acesso em: 25 maio 2012.

ROUSSEAU, Jean-Jacques. Do contrato social. Trad. Samuel Ramos. México: Fondo de Cultura Económica, 1994.

SCHMITT, Carl. Verfassungslehre. 5. ed. Berlim: Duncker \& Humblot [reimpressão inalterada da $1^{a}$ edição, de 1928] trad. esp.: Teoria de la Constituición. México: Nacional, 1970.

STF. Supremo Tribunal Federal. Ação Direta de Inconstitucionalidade n. 3330-1. Cotas raciais em instituições de ensino superior. Democratas - DEM, Confederação Nacional dos Estabelecimentos de Ensino - CONFENEN, Federação Nacional dos Auditores Fiscais da Previdência Social - FENAFISP x Presidente da República. Rel. Min. Ayres Brito. Disponível em: <http://www.stf.gov.br/arquivo/cms/noticiaNoticiaStf/ anexo/adi3330CB.pdf>. Acesso em: 11 maio 2012.

\section{SYMBOLIC CONSTITUTION: THE DISCREPANCY BETWEEN THE \\ CONSTITUTIONAL SYMBOLISM AND ITS LEGAL-NORMATIVE \\ INEFFECTIVENESS}




\begin{abstract}
This work shows a study about of the "Symbolic Constitution: the discrepancy between the constitutional symbolism and its legalnormative ineffectiveness". It will address the issue discussing the substantial discrepancy between the symbolism involved in the Brazilian Constitution and its legal-normative ineffectiveness, much because to the influence the political-symbolic function, using as basic foundation the work of Pierre Bourdieu, referencing, obviously, others theoretical to complement the focal points of the topic. From a systematic-deductive approach on the topic, it's possible to identify the substantial discrepancy between the symbolism involved in the constitutional text and its normative-legal inefficiency caused by the influence of political-symbolic function.
\end{abstract}

Keywords: Symbolic Constitution. Constitutionalization. Symbolic. Symbolic Legislation. Legislation-alibi. 